\title{
Announcement
}

\section{Medical Principles}

and Practice
Med Principles Pract 2001;10:162

\section{Recent Advances in Infertility Management: A Multidisciplinary Approach}

March 9-11, 2002

Sponsor: Faculty of Medicine, Kuwait University

Co-Sponsors: Kuwait Institute for Medical Specialization (KIMS)

Location: Sheraton Hotel, Kuwait

Topic(s): Genetic Basis of Male and Female Infertility,

Polycystic Ovarian Syndrome: Optimizing Protocol for

Induction of Ovulation, Assisted Conception and Complications,

Sex Preselection

Guest Speakers: From United States of America,

United Kingdom, Canada, Belgium, France and Australia

Fee: None

Deadline for submission of abstracts: December 1, 2001

Deadline for registration: December 31, 2001

\section{Contact:}

Dr. Magda K. Al-Azemi

Department of Obstetrics and Gynaecology

Faculty of Medicine, Kuwait University

PO Box 24923

13110 Safat (Kuwait)

Tel. +965 5319601, Fax +965 5338906

E-Mail alazemimajda@hsc_kuniv.edu.kw

\section{KARGER}

Fax + 41613061234 E-Mail karger@karger.ch www. karger.com
(C) 2001 S. Karger AG, Basel

1011-7571/01/0103-0156\$17.50/0

Accessible online at:

www.karger.com/journals/mpp 